\title{
Qualitative Study of First-Generation Latinas: Understanding Motivation for Choosing and Persisting in Engineering
}

\section{Dina Verdin, Purdue University}

Graduated with my B.S. in Industrial and Systems Engineering from San Jose State University. Currently, I am a Ph.D. student in Engineering Education at Purdue University.

\section{Dr. Allison Godwin, Purdue University, West Lafayette}

Allison Godwin, Ph.D. is an Assistant Professor of Engineering Education at Purdue University. Her research focuses on increasing female enrollment in engineering, how students' attitudes and beliefs affect their choices and their learning, and how to improve engineering education for all students - especially those from underrepresented groups. Dr. Godwin graduated from Clemson University with a B.S. in Chemical Engineering and Ph.D. in Engineering and Science Education. She is the recipient of a 2014 American Society for Engineering Education (ASEE) Educational Research and Methods Division Apprentice Faculty Grant. She also was an NSF Graduate Research Fellow for her work on female empowerment in engineering which won the National Association for Research in Science Teaching 2015 Outstanding Doctoral Research Award.

\section{Dr. Jennifer Lynne Morazes, Brandeis University}

Dr. Jennifer Lynne Morazes currently serves as the Director of Student Support Services at Brandeis University, where she oversees an initiative supporting 150 first-generation and low-income students. In her previous role as Educational Counselor and Adjunct Faculty at San Jose State University, she founded the GENERATE initiative which was featured in the Chronicle of Higher Education Diversity in Academe 2013 Issue. Her research on first-generation college students considers the role of stressful circumstances on academic success. Dr. Morazes earned her PhD in Social Welfare and MSW from the University of California, Berkeley School of Social Welfare. 


\title{
Qualitative Study of First-Generation Latinas: Understanding Motivation for Choosing and Persisting in Engineering
}

\begin{abstract}
Latina undergraduates pursuing an engineering degree continue to be an underrepresented group at four-year universities. Compared to their male counterparts, fewer women enter the field of engineering; however, of those Latino/as who do matriculate, they have the same likelihood of persisting as their White counterparts. Furthermore, a dearth of underrepresented students such as Latino/as and first-generation college students enter or remain in the field of engineering. The need for increased gender and racial/ethnic representation in engineering is a documented need allowing for the production of a wider range of innovative products that take into consideration different perspectives that represent the make-up of the nation as a whole. Recent studies demonstrate that Latinas who are enrolled in the field of engineering remain in engineering at higher rates than other ethnic minorities.
\end{abstract}

In order to increase and retain greater ethnic and gender diversity in engineering, this research seeks to examine what motivates first-generation Latinas in engineering at an urban public university to pursue engineering and persist. Past research has investigated the experiences of first-generation students more generally, without distinguishing specific populations or their choice of study. In addition, several studies investigate why first-generation and underrepresented students drop out of college; some have found that it is due to an unclear purpose for college, adjustment issues to the college environment, and feelings of isolation. The perspectives of first-generation Latina engineering students are captured through conducting eight qualitative in-depth interviews and through analyzing their narratives. This research elucidates some of the reasons why Latinas choose engineering in college and why they continue in engineering using Achievement Goal Theory (AGT) as the theoretical framework. This theory posits that goals are cognitive accounts of what a person tries to accomplish and one's purposes or reasons for doing the task. This research demonstrates that participants displayed a higher sense of purpose, not only in mastery and performance, but also in a sense of self-reliance and intellectual self. This research serves as a point of departure towards highlighting ways in which the field of engineering can become a more desirable major for first-generation Latina women. The results of this work point to specific methods for accomplishing this goal.

\section{Introduction}

\section{Underrepresentation in Higher Education}

Latino/as are considered to be the largest racial and ethnic group in the United States, comprising of $15.4 \%$ as of 2008, with African American and Asian population increasing at a slower rate ${ }^{46}$. The Latino/a population are expected to continue growing, at faster rates than most other race/ethnic groups, in 2025 they will comprise of around 21 percent of the population ${ }^{46}$. As these increases continue, it can be expected that there will also be an increase in college enrollment for this population. The National Center for Education Statistics reported college students enrolled in 2007-2008 whose parents had a high school diploma or less were as follows, 25 percent of 
White parents, 32.2 percent of Asian parents, 35.6 percent of Native American parents, 45 percent of African-American parents, and 48.5 percent Latin American parents ${ }^{38}$. Therefore, almost 50 percent of the students enrolled in that year were first-generation college students of Latino/a origin. As access to higher education is increasing for the Latino/a population, there remains a concerning issue of graduation rates. Between 1996 and 2008 there was only a 4 percent increase in Latino/as adults who earned a bachelor's degree ${ }^{46}$. Overall, of the Latino/a adults between the ages of 25 and 29 in 2008, only $11 \%$ held a bachelor's degree; compared to $33 \%$ Whites and $17 \%$ African Americans ${ }^{46}$.

For these reasons, the unique experiences and challenges that first-generation students face in the higher education system merit research attention. According to the U.S. Department of Education, first-generation college students are classified as students who come from families where neither parent obtained a four-year college degree ${ }^{40}$. From the statistics cited above, firstgeneration college students are more likely to be of Latino/a origin. This group of firstgeneration college students, historically, has not had as high educational attainment as majority groups have. As the population of Latino/as continues to grow it can be projected that this group will experience significant growth and supersede other populations in college enrollment ${ }^{23}$.

One study investigated the effects of whether American universities cultural norms (i.e., norms of independence) serve as a disadvantage for first-generation college students ${ }^{35}$. The study revealed a cultural mismatch among first-generation college students due to their tendency to possess norms of interdependence, which are not consistent with American universities' norms of independence ${ }^{35}$. Additionally, numerous national studies have documented achievement gaps between first-generation students and their counterparts in four-year degree programs with firstgeneration students typically falling behind their peers ${ }^{15,35}$. First-generation college students lack many privileges that their counterparts possess in pursuing a four-year degree. Among these privileges are parents with insider knowledge of the college process and protocols, study skills, and contacts with mentors in the college system ${ }^{15,37,44}$. As a result, first-generation college students lag behind their counterparts in GPA, progress toward their chosen degree, and completion of degree programs ${ }^{15}$.

National trends demonstrate that first-generation college students, in comparison to their counterparts, are more likely to be from a lower socioeconomic status, be older, earn lower SAT scores, and not participate in honor programs ${ }^{3}$. First-generation students also commonly attain lower grades in college, take fewer credit hours, and have greater dropout rates when compared to students who have at least one parent with a 4-year degree ${ }^{30,35}$. Low academic performance for this population has also been apparent in courses such as mathematics, science and computer science. For example, on average, $\mathrm{Chen}^{3}$ reports that first-generation students majoring in science and mathematics earned a 2.5 GPA and 2.6 GPA, respectively, as opposed to students whose parents completed college, who earned a 2.9 GPA and 3.1 GPA, respectively. Overall, studies have concluded that individuals with well-educated parents may have a distinct advantage in understanding the culture of higher education, the role it plays in their personal development, and consequent socioeconomic attainment ${ }^{30}$. 


\section{Underrepresentation in Engineering}

The underrepresentation of racial/ethnic groups is a common problem throughout multiple disciplines; however, women of all racial/ethnic groups in engineering are some of the most underrepresented people of any discipline. In 2013 , women made up $19.1 \%$ of the overall engineering bachelor's degree recipients, while Latino/as made up $9.3 \%$ of the engineering degrees awarded ${ }^{43}$. Engineering, according to researchers, continues to be acknowledged as predominantly White and male ${ }^{32,36}$. According to Landis $^{20}$, the average retention rate in engineering schools for minorities is only 30 percent, while Caucasians have an approximately 50 percent retention rate. When it comes to women from diverse racial backgrounds in science and engineering departments, they are nearly absent. As stated by some researchers, "Minoritygroup women are subject to dual discrimination and face even more barriers to success," 26, p.3. This research demonstrates that women scientists, despite being highly productive and wellqualified, have had to accept continuous questioning of their abilities in math and science which affects their achievement in their fields. For example, Sally Ride, an astronaut and physics professor, commented that one reason girls tend to lose interest in science and math is due to the social pressures and stereotypes after elementary school, girls tend to lose interest in science and math $^{18}$. Because of this bias, racial/ethnic women do not develop their abilities and interest to the fullest because they have not been given the opportunities and encouragement that have been afforded to race-privileged men $^{18}$.

The Multiple-Institution Database for Investigating Engineering Longitudinal Development (MIDFIELD) can help shed light on the trajectories of Latino/as in engineering. This dataset overall includes 10 institutions, seven of which are engineering institutions with over $20 \%$ engineering enrollment (higher than the national average of 9\%). As a result, data from this group overcomes the limitations of small data sets that are unable to disaggregate groups by race and gender due to low statistical power. The results extrapolated from the MIDFIELD database are generalizable across the same type of institutions, large public universities with high averages of engineering enrollment ${ }^{2}$. Studies using this dataset found that both genders who matriculated in engineering have higher eight-semester persistent rates than other majors do; women of all races (except Native American) remain in engineering at comparable rates than of men ${ }^{28}$. The data gather from MIDFIELD shows no persistence gap between Latino/as, however, it should be noted that the number of women, and Latinas specifically, entering the field of engineering are quite ${ }_{\text {low }}^{2}$. A common misconception about engineering may be that retention is the largest obstacle students need to overcome; however, this data has proven otherwise. The high persistence rate of Latino/as may be unique to the field of engineering, that is, the type of students drawn to engineering have higher inclination towards successful persistence ${ }^{2}$.

By examining the interplay of first-generation status and race/ethnicity, the system of engineering education can be examined and specific changes can be made to improve the experiences of these underrepresented groups ${ }^{4}$. While underrepresented students are encouraged to pursue a college degree in order to gain entry into higher-wage jobs, first-generation students start at a disadvantage compared to their fellow non first-generation peers due to background factors. Furthermore, the challenges experienced by first-generation students, in part, explain higher drop-out rates after their first year, longer time to degree completion and less than satisfactory first-time employment opportunities ${ }^{34}$. 


\section{First-generation Students in Engineering}

In recent years, there has been an increased desire to diversify the field of engineering at the undergraduate level to improve the representation of engineering solutions to better reflect the demographics of the U.S. population ${ }^{42}$. However, there are few actions targeting explicitly firstgeneration college students in engineering, this population is not specifically targeted in typical recruitment or outreach efforts, although this group has been growing in numbers and offer significant opportunities to the nation's engineering workforce ${ }^{23}$. First-generation college students are more likely to be of Hispanic origin and historically, this group has not had as high educational attainment as majority groups. In the years to come, this group is projected to grow significantly and will soon outweigh other populations in college enrollment ${ }^{23}$. This increase will likely result in not only more Latino/as in college, and many of these students will also be first-generation college students. Little research has been conducted specifically on students at the intersections of these two designations. A study seeking to identify and explore barriers perceived by first-generation students majoring in engineering, found similar experiences between engineering students and other fields, the only difference being the stringent demands of the curriculum ${ }^{12}$.

\section{Intersections of Ethnicity, Gender, and First-generation Status}

The introduction section of this research paper discusses a variety of factors that influence students who sit at the intersections of race/ethnicity, gender, and first-generation student status. Understanding the reasons for why students in the intersection of first-generation students and students of color can illustrate ways to improve undergraduate education for this underrepresented group. Additionally, research focusing on first-generation students does not necessarily apply to students who are also Latina and vice versa. This paper focuses on firstgeneration Latina students entering four-year degree programs at the intersections of all these barriers into participation into engineering. Demographics suggest that Latinas can make a significant impact in engineering education since they are the fastest growing minority group in the United States. Women continue to be underrepresented in engineering, computer science, and physics. Since little is known about academic and personal experiences of first-generation Latinas in engineering, this paper seeks to understand the unique experiences, challenges, and motivation of this student population. Achievement Goal Theory may assist in delineating and understanding the motivation of these women in engineering ${ }^{45}$.

\section{Achievement Goal Theory}

This study used Achievement Goal Theory (AGT) to provide insight into how motivational constructs are interconnected and influence student achievement and choice of engineering in college. AGT has been extensively utilized for understanding college students'

motivations $\mathrm{s}^{41,47,49}$, however it has not yet been widely used to research the motivation of diverse populations, especially first-generation Latinas in engineering. ${ }^{45,48}$ According to $\mathrm{Yu}$ and colleagues, "understanding contextual and cultural factors related to motivation is one of the key substantive issues for researchers in motivational science" ${ }^{45}$. Ethnic identity and first-generation status are two intersecting factors that affect motivation. Motivation is a powerful construct that can highlight ways in which at these two intersections choose and persist in engineering by 
highlighting underlying reasons for why students choose particular actions.

Achievement Goal Theory has emerged as a primary theoretical framework for understanding motivation in academic settings ${ }^{31}$. Goal theory, developed from normative goal theory, includes two dichotomous achievement goals: mastery and performance goals. Researchers have labeled mastery goals as task and learning goals, while performance goals are considered ego and ability goals ${ }^{6,11,27}$. Achievement Goal Theory has been influenced and cultivated by three important motivational frameworks: social-cognitive theory, attribution theory, and achievement motive tradition. From this theory, goals are cognitive accounts of what a person tries to accomplish and one's purposes or reasons for doing the task. Goals that are specific to task orientation or a more general goal approach are applied to several different situations or type of goals such as happiness or safety, but achievement goal constructs elucidate achievement motivation and behavior $^{31}$. These constructs include a number of related beliefs about purpose, competence, success, ability, effort, errors, and standards in regards to the achievement of a goal ${ }^{31}$. In short, AGT is more interested in why students try to achieve a particular goal and is less focused on the goal itself. For example, if a student is trying to get an "A" in his/her course, AGT would suggest possible reasons for striving towards this goal. One reason could be that the student wants to learn and understand the material, that the student believes earning an " $\mathrm{A}$ " indicates mastery of the content, or that the student wants to appear "smart" or "successful." Achievement Goal Theory is used in this study to understand students' motivation for successfully navigating their experiences in engineering.

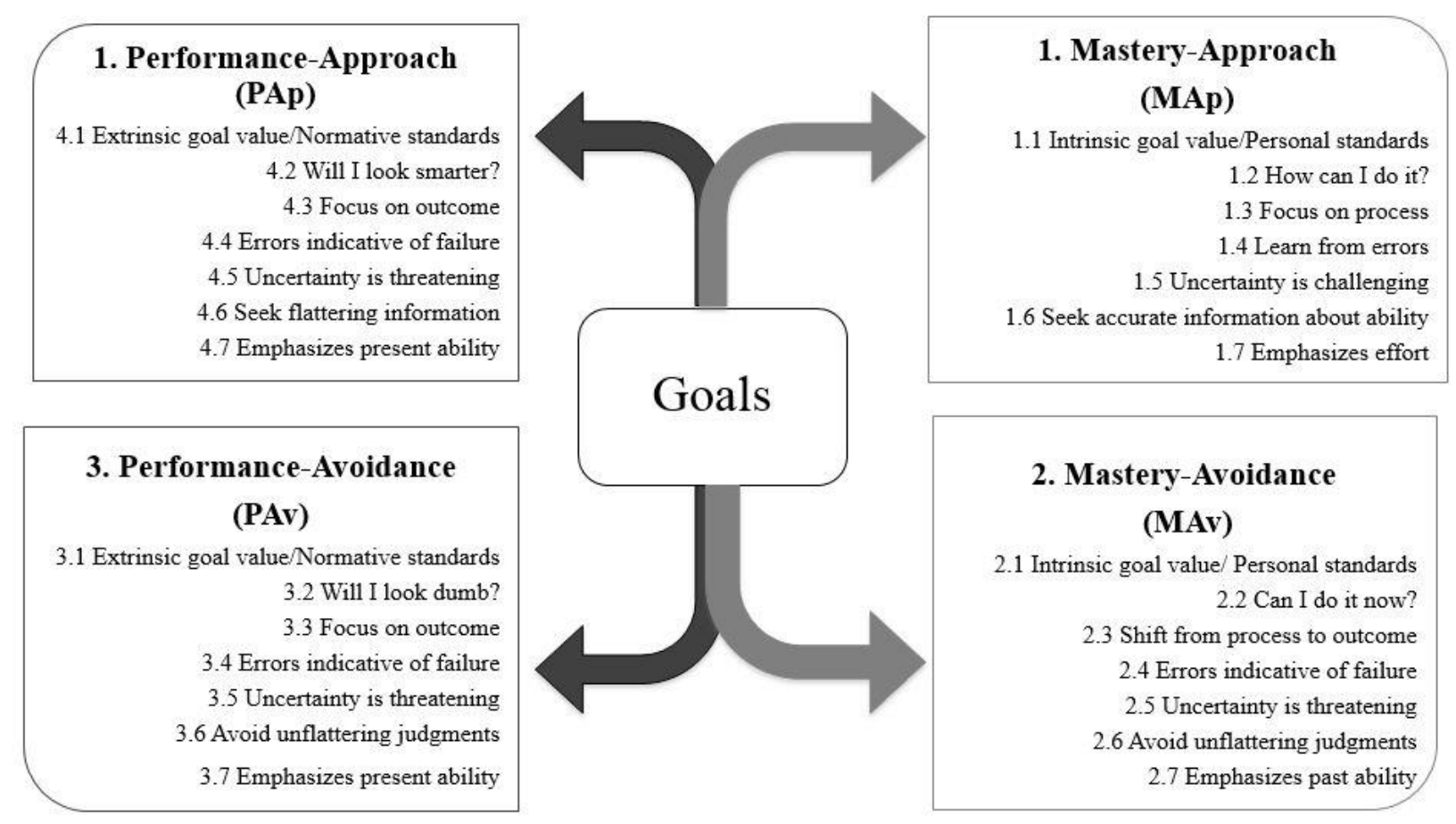

Figure 1: Model of Achievement Goal Theory ${ }^{41}$.

Figure 1 presents AGT as conceptualized by Wentzel and Wigfield ${ }^{41}$. The two elements of mastery and performance are bridged to create a framework consisting of four overall 
achievement goals: mastery-approach (MAp), mastery-avoidance (MAv), performanceapproach (PAp), and performance-avoidance (PAv) ${ }^{41}$. When a MAp goal is adopted, individuals try to build upon their competence by striving to master the skill. Approach and avoidance are fundamental distinctions applied to various types of goals. In educational psychology, the common goal used is achievement goal, which emphasizes competence. In turn, competence is defined by the standards used to evaluate it, which are "absolute (requirements of the task itself; task-based) or intrapersonal (one's own past attainment or maximum potential attainment") standards. However, both absolute and intrapersonal standards are said to "collapse" together into what is referred to as mastery goals. Thus, research suggest that competence can be defined by the following whether "one has acquired understanding or mastered a task (an absolute standard); improved one's performance or fully developed one's knowledge of skills (an interpersonal standard)"10, p.501. Absolute and intrapersonal competence have been considered, by researchers, as joint standards because they parallel both conceptually and empirically ${ }^{10}$. A MAv goal is performed out of desire to avoid self-referenced or task-referenced lack of skill; for example, when a student tries not to perform a skill more poorly than before. The adoption of PAp goals entails the desire to do better than others, or to achieve normative competence. On the other hand, PAv goals are set by students who want to perform out of a risk/fear of looking incompetent. In short, both approach goals are centered on reaching success, while the two avoidance goals focus attention more on avoiding failure ${ }^{41}$. In addition, the two mastery goals implicate self- and task-referenced definitions of ability, while both performance goals involve normative definitions of ability ${ }^{10}$. The commonalities of the four-achievement goals are shown in Table 1.

Researchers, Harackiewicz, Barron and Elliot ${ }^{17}$, have effectively used AGT to link motives and achievement goals. While the emphasis of the difference or lack of difference between effort and ability was the focus of attention in Nicholls ${ }^{27}$ work, and the focus on competence was highlighted by Elliot and Church ${ }^{8}$. This theory has been applied in order to understand perceptions of the classroom environment and students' motive to approach success which is connected to mastery goals ${ }^{1,8}$. In specific contexts, AGT has elucidated the behavior of students in physical education, collegiate sports, mathematics courses, and even engineering students ${ }^{41}$. This study makes a unique contribution to our understanding of motivation applying AGT to underrepresented student populations, specifically on first-generation Latina students in engineering to understand ways in which they adopt motivational profiles for success. This study seeks to address the gap in the literature by considering how being a first-generation female minority student relates to mastery and performance approach and avoid constructs through their personal narratives that describe their choice and persistence in engineering. 
Table 1: Approach and Avoidance states of Achievement Goal Theory ${ }^{31}$.

\begin{tabular}{|c|c|c|}
\hline & Approach state & Avoidance state \\
\hline \multirow[t]{2}{*}{ Mastery orientation } & $\begin{array}{l}\text { Focus on mastering task, } \\
\text { learning, understanding }\end{array}$ & $\begin{array}{l}\text { Focus on avoiding misunder- } \\
\text { standing, avoiding not learn- } \\
\text { ing or not mastering task }\end{array}$ \\
\hline & $\begin{array}{l}\text { Use of standards of self- } \\
\text { improvement, progress, } \\
\text { deep understanding of task }\end{array}$ & $\begin{array}{l}\text { Use of standards of not being } \\
\text { wrong, not doing it incor- } \\
\text { rectly relative to task }\end{array}$ \\
\hline \multirow[t]{2}{*}{ Performance orientation } & $\begin{array}{l}\text { Focus on being superior, best- } \\
\text { ing others, being the smart- } \\
\text { est, best at task in } \\
\text { comparison to others }\end{array}$ & $\begin{array}{l}\text { Focus on avoiding inferiority, } \\
\text { not looking stupid or dumb } \\
\text { in comparison to others }\end{array}$ \\
\hline & $\begin{array}{l}\text { Use of normative standards } \\
\text { such as getting best or high- } \\
\text { est grades, being top or } \\
\text { best performer in class }\end{array}$ & $\begin{array}{l}\text { Use of normative standards } \\
\text { of not getting the worst } \\
\text { grades, being lowest per- } \\
\text { former in class }\end{array}$ \\
\hline
\end{tabular}

\section{Purpose of Study}

Many majors and professions, particularly those related to math and science, have traditionally lacked representation of women and people of color. Although there has been considerable progress toward gender parity in the natural and biological sciences, women continue to be underrepresented in the engineering and computer science fields ${ }^{39}$. Even though these disparities persist, little is known about academic and personal experiences of racial minorities and firstgeneration women in sciences, particularly first-generation Latinas. Across all underrepresented minorities, Latino/as are said to have the greatest potential impact in the engineering field since they are considered America's largest minority population ${ }^{2}$. This demographic suggest that Latino/as have a potential to diversify the engineering workforce, however further research is warranted to increase knowledge of how to advance Latino/as achievement in the STEM fields, in order to meet the demands of the rapidly growing global market ${ }^{2}$. Therefore, the purpose of this small-scale pilot study of first-generation Latinas at an urban public university in the South Bay of California is to begin building this requisite knowledge by seeking to understand the motivation of first-generation Latinas in engineering. Since an issue in engineering is not retaining Latinas, instead it is recruiting them, this study seeks to understand the specific motivations for pursuing an engineering degree and the mechanisms for high persistence rates among this group. Although it is a small-scale study, this research will serve as a beginning point of departure for making better informed decisions about the allocation of resources, educational programming and support systems for first-generation Latina students in STEM professions. This research can begin discussion on the formulation of best practices about how to improve retention, achievement, undergraduate graduation rates, and career preparation of first-generation Latinas in engineering. This research may elucidates some of the reasons why Latinas choose engineering in college and why they continue in engineering using Achievement Goal Theory (AGT) as the theoretical framework. 


\section{Research Questions}

In this paper, we used the lens of AGT to address the following research questions:

1. How do first-generation Latinas' motivation orientations affect engineering choice?

2. How do first-generation Latinas' motivation affect persistence in engineering?

\section{Methodology}

This pilot study uses a qualitative multiple case-study interview approach as a form of data collection and analysis. As established by Kuzel ${ }^{19}$, this method is particularly appropriate for describing the first-hand experiences of the population of interest, in our case, first-generation Latinas in engineering. Methods used in qualitative research studies allow for the researcher to explore an event in a more spontaneous and flexible way. These techniques are practical and appropriate for this research, for the "generation of categories for understanding human phenomena and the investigation of the interpretation and meaning that people give to events they experience" and allows for rich and in-depth findings on the subject matter ${ }^{33}$ p.112. This method of research yields three fundamental propositions (1) naturalistic investigation, (2) inductive reasoning, and (3) a holistic outlook ${ }^{33}$.

The focus of this study is to explore the participants' experiences and motivation in engineering, not to explore the culture of engineering itself. Individual interviews presented a better opportunity to acquire a holistic understanding of the participants' experiences as a firstgeneration Latina in this field. As stated by Creswell, "Qualitative research is a means for exploring and understanding the meaning individuals or groups ascribe to a social or human problem" (p.4) . This study identified the connections between students' motivation profiles and experiences in engineering by mapping questions from a larger study to the framework of AGT.

\section{Study Participants}

Eight participants were recruited and interviewed from the Mathematics Engineering Science Achievement (MESA) Engineering Program, in the South Bay area, which is an academic program that supports educationally disadvantaged and first-generation college students to attain a degree in engineering or computer science by creating a peer community. The eight participants were in their Junior or Senior year in engineering and were also first-generation Latinas. Upperclassmen were chosen because research demonstrates that students at the juniorlevel are a reliable representation of persisters because they are unlikely to change majors at this point in their undergraduate career ${ }^{29}$. As part of gathering information about demographics/background, participants were asked about their country of origin, age, birthplace, current year in college, type of engineering major, parents' educational status, and financial aid status. This study included transfer students as well as students who came in as freshmen, because the community college path was an important factor to consider when studying Latino/as in higher education. Latino/as tend to enroll at a community college at higher rates than Whites or Black counterparts, at 44 percent of all college going Latino/as². However, the pattern of persistence for transfer students merits an additional independent analysis because they have been shown to follow a different educational path ${ }^{21}$. 


\section{Data Collection and Analysis}

Students participated in one-hour interviews with a semi-structured interview protocol created to facilitate a conversation with the participants (see Table 2). These questions were developed to understand first-generation Latinas' experiences in engineering and to elicit their stories as part of a larger study. In this research, the AGT framework was used to map these stories onto the four subconstructs of AGT to understand specific mechanisms of motivation in students' experiences. The fundamental model of the qualitative research study is that the experiences under study should unfold through the participant's eyes ${ }^{22}$. The questionnaire served the following purposes: (1) to provide structure and organization in order to ensure each topic was covered in the same order for each participant, (2) to establish a station for direction and possibility of dialogue, and (3) to protect the overall arrangement and purpose of the interview ${ }^{24}$. Participants who fulfilled the study criteria were interviewed individually in a reserved study room at the university library. Participants were given a consent script to read that highlighted the voluntary nature of the interview, purpose of the study, and any potential risks involved. Participants read and signed the informed consent form, agreeing to participate in this study. Participants filled out a brief demographic questionnaire and then answered semi-structured interview questions. Each participant was reminded that they could pass on any question. All research procedures were approved by the university Human Subjects Institutional Review Board.

The data analysis involved systematic, sequential comparisons of the different narratives in order to develop possible relations between various experiences. Interviews were transcribed verbatim, and data were organized and coded digitally using Microsoft Word and Excel Spreadsheets. During the analysis of the data, inductive coding was conducted allowing common topics to emerge and later collapsed into overarching themes that added to the understanding of this analysis. Additionally, deductive coding using the motivation categories from AGT was conducted as the analysis for this specific study.

Table 2: Semi-Structured Interview Protocol

Discuss your reasons for choosing your field of engineering as a major.

Influential individuals? Role models?

Related hands-on experiences? Exposure?

Role of guidance counselors? Teachers? ${ }^{16}$

Do you ever feel like you do or do not belong in this major? Why or why not?

Describe your experiences in the engineering classroom, beginning with the first year?

Role of faculty?

Role of advisors?

Role of peers? ${ }^{16}$

How do you feel when you share with others that you are Engineering major? How do people react?

Did you ever consider changing your major? Why or why not?

What motivates you to continue studying engineering? 
Do you feel you are at an advantage or disadvantage than your fellow peers in your major? Why or why not?

Do you often question your abilities in class, lab or study groups? Why or why not? Give me some examples.

Describe how certain were you in choosing engineering as a major? Belief of capability. Early perceptions of the field ${ }^{16}$.

Do you feel you are treated differently by peers, staff and/or professors for being an Engineering major? Please describe why or why not?

\section{Confidentiality}

Every measure to ensure confidentiality was taken to ensure the privacy of each participant. All participation was voluntary. Each adult participant was fully informed about the nature of the research, what was required, and any possible stresses and benefits involved. They had the right to withdraw without prejudice with their relations with the university. All signed consent forms included information allowing participants to access the appropriate staff at the university if problems were encountered during the study. Each interviewee was assigned a code number to protect their identity which was only accessible to the research team. A log sheet with code numbers and names was kept separate from the questionnaire in a secure location. Any working keys such as names and phone lists used to keep track of participants during the project, as well as audiotapes, were kept in a locked office room. Consent forms did not include the code number in order to protect confidentiality. In the case of publication, no identifiable information, such as names, were used. In the case of using direct quotes, the participant's identity was disguised. Also, audiotapes were destroyed at the end of the study.

\section{Results and Discussion Sample Demographics}

To understand the background factors for participants, a simple demographic survey was administered to collect information on a number of different characteristics. This information included: students' engineering discipline, ethnicity, current number of years in college, financial aid status, transfer school status, and the parental level of education. This information is presented in Table 3.

Table 3: Sample Demographics

\begin{tabular}{|l|l|l|l|l|l|l|l|}
\hline & & & & & & \multicolumn{2}{|l|}{ Parents' Education } \\
\hline Code & Major & Ethnicity & $\begin{array}{l}\text { Attended } \\
\text { College }\end{array}$ & $\begin{array}{l}\text { Transfer } \\
\text { Student }\end{array}$ & $\begin{array}{l}\text { Financial } \\
\text { Aid }\end{array}$ & Father & Mother \\
\hline U1 & Electrical & Mexican & 5.5 years & Yes & No & $\begin{array}{l}\text { Middle } \\
\text { School }\end{array}$ & $\begin{array}{l}\text { Middle } \\
\text { School }\end{array}$ \\
\hline U2 & Mechanical & $\begin{array}{l}\text { Salvadorian/ } \\
\text { Filipino }\end{array}$ & 5 years & No & No & $\begin{array}{l}\text { Some } \\
\text { College }\end{array}$ & $\begin{array}{l}\text { High } \\
\text { School }\end{array}$ \\
\hline U3 & Chemical & Mexican & 5 years & Yes & Yes & $4^{\text {th }}$ grade & $6^{\text {th }}$ grade \\
\hline U4 & Civil & Salvadorian & 6 years & Yes & Yes & $\begin{array}{l}\text { High } \\
\text { School }\end{array}$ & $\begin{array}{l}\text { High } \\
\text { School }\end{array}$ \\
\hline
\end{tabular}




\begin{tabular}{|c|c|c|c|c|c|c|c|}
\hline U5 & Industrial & Mexican & 7 years & Yes & No & $\begin{array}{l}\text { Bachelors } \\
\text { in Mexico }\end{array}$ & $\begin{array}{l}\text { Middle } \\
\text { School }\end{array}$ \\
\hline U6 & Mechanical & Mexican & 3 years & No & No & $\begin{array}{l}\text { Middle } \\
\text { School }\end{array}$ & $\begin{array}{l}\text { Middle } \\
\text { School }\end{array}$ \\
\hline U7 & Biomedical & Mexican & 4 years & Yes & Yes & $6^{\text {th }}$ grade & $\begin{array}{l}\text { Some } \\
\text { High } \\
\text { School } \\
\end{array}$ \\
\hline Graduate & & & M.S & & & & \\
\hline G1 & Electrical & Mexican & 3 years & No & No & $\begin{array}{l}\text { Middle } \\
\text { School }\end{array}$ & $\begin{array}{l}\text { Middle } \\
\text { School }\end{array}$ \\
\hline
\end{tabular}

\section{Mastery Orientation}

Participants were asked to describe the reason why they chose engineering and how they were exposed to it. The accounts of some students suggested a mastery approach towards their motivation. Students that have adopted this goal may show higher perceptions of academic competence than other students. For example:

I feel like I belong to the major because of the things that I'm learning, especially in the manufacturing class, it's all about system improvements using statistics and I like improving things, making them better, making them fast and analyzing, giving the results in numbers. I like that kind of stuff [U5].

This students' quote illustrates mastery approach in her desire to learn concepts and become proficient in engineering-related skills. Past studies have found benefits of pursuing mastery approach goals, mostly due to its role in "fostering interest in academics" student shared,

"I wanted to do something that had to do with education helping the students, bringing more Hispanics into science, I knew that, so I started to question myself, why do I really want to do this, if I do engineering I can get a really good job and be a role model for other students, not only will I be doing science itself, but it's going to be engineering" [U3].

This participant's interest in becoming an educator indicates she wanted to learn the material not just to pass the class, but to become proficient in the subject to one day teach it to others.

According to Meece and colleagues ${ }^{49}$, mastery goals have been positively associated with how a student perceives him/her academic ability and self-efficacy.

"for me I'm the kind that likes a challenge I like to be in a challenging major,... I know there is a lot of praise in doing engineering, but I don't want the praise to be because I'm a women doing engineering... I know I'm a girl but it shouldn't be extra amazing it should just be that oh okay you're doing 
engineering that's cool but uh it helps cause in my mind yea I can do this and everyone thinks it's hard so having people

acknowledge that its hard is good" [U2].

The mastery avoidance state is not focused on how one's performance is compared to others, but how one's present performance compares to one's personal standards for achievement based on past accomplishments. In the following account a student focused on her high school achievement, she emphasized her own past ability to her future achievement in college.

I was a 4.0 student in high school, but my first test in college I failed because I didn't know the system, it took me some time to get used to it.... It was calculus, I went to go talk to the professor, I said I just didn't know what I was doing, I know how to do this, I have taking calculus before, I just got nervous and I ended up getting a B+ in that class, which is huge [G1].

This student addressed that her level of competence prior to arriving to college was at a 4.0, signifying that her motivation was not to perform better, but rather to avoid under-performing. Prior research has also shown that that students who assume the mastery avoidance goal have achieved success in the past, which clearly illustrated in this student's narrative ${ }^{41}$. Uncertainty for this participant was a threatening factor towards her goal, as she stated, "you don't know what the future holds for you or the job, you don't know if you're going to like... you have to put in your time as an individual contributor and then move up that ladder [G1]. Mastery avoidance indicated uncertainty as a threatening factor towards achieving one's goals; however, it did not deter this student from accomplishing her goals, but rather it served as a motivating factor.

\section{Performance Orientation}

Although the two mastery goals implicate self- and task-referenced definitions of ability, both performance goals involve normative definitions of ability ${ }^{10}$. In one narrative, a student chose her goal in relation to other's perception of math's normative difficulty, suggesting performance orientation:

In elementary school, I really liked math, so I was like okay I'm going to be a math major, I'm going to get a math degree and my dad was like, 'yea, you can use math for everything,' so he always encouraged me, all my friends were like, 'you're going to do math that's hard' [U2].

The same student makes a statement underlying that her motivation may be geared towards selfimprovement or performing at a higher level than her peers.

"my advantage is that I'm always willing to take a step back and say maybe I don't have it right maybe I should consider and talk to everyone around me before I start saying this is it, and also my major thing is being able to listen and hear people 
out and I never do too many spontaneous quick decisions, even though I like being a spontaneous person, when it comes to school work and projects and anything team wise I like to think everything out and be very methodical in how things are done cause with engineering they are always telling us you can kill someone if you don't do things right of if you don't pay attention," [U2].

Performance-orientated students may seek compliments from their counterparts for the type of achievement they are accomplishing to validate their goals as was the case with this student. Goals indicating performance approach entail the desire to do better than others. This may come from outright competition with others, or judging others that are perceived to fall short.

In another account, the following student described her motivation for continuing in her major:

I look at other people and its funny cause I think those who do change their major, I think their weak or not committed, I'm sorry, but that's the truth, commit, just do it, nothing comes easy, nobody gives you anything for free you need to work for it [G1].

This account did not focus on mastering the subject matter, but rather it emphasized her desire to perform by being committed to the goal at hand in relation to the commitment of others. This same student reported that, "Because the people are very different, I found myself being the only Latina in a lot of the labs, a lot of the classes, but I don't know, it was a challenge for sure, but I think I like challenges cause it kind of pushed me to complete the major and get the highest grades in the class" [G1]. This meaning of this comment suggested that the driving motivational factors for this student was her desire to outperform the other students.

Inversely, performance avoidance is centered on the idea of not performing poorly, avoiding the feeling of inferiority to others. One student expressed this form of motivation:

I think this is more of the way, ... I like to ask questions, but ...

I don't know I get really embarrassed because I really want to know it well, but when I don't get it, I don't want to call attention to the fact that I'm not getting it, so it's a lot harder for me to ask teachers for questions unless I have done a lot of research and I tried really, really hard, so in class if I don't get it, I usually differ or ask a friend, so I think it's more calling attention to it in a teacher student setting [U2].

This goal orientation state proved to be problematic for this student. By adopting the avoidance performance goal she was limited in her ability to learn the required material and participate in class because of her fear of looking incompetent relevant to others. 
As this student focused on achieving high levels of performance in her homework, she was met with some resistance from her classmates.
"I would get really mad, like my friend Danny's friend when we would do homework he would automatically tell me no it's not that way and I would get really, really mad because ... I was like well you just cant keep telling me no without telling me why so I kind of just stop doing homework with them because it was getting really frustrating" [U2].

How students are evaluated in their classwork can affect motivation. The following is an example of a student's narrative of how she was evaluated on her performance and her resistance:

"A professor once told me asked if I really want to do this
because I'm not really good at it, he said 'it doesn't look like you
did good in this class, ' no this is what I want to do there are
other things affecting my life not just school, I don't want to do
anything else I see myself only doing this, these are just classes,
my professors do ask me 'you don't want to change your
major?'"' [U7].

Using the framework of AGT for deductive coding, these narratives were analyzed to understand the reasons first-generation Latinas chose engineering and were motivated to persist in their chosen field. Overall, participants in this study demonstrated a strong sense of purpose in their engineering paths. Having a mastery goal orientation produced greater effort during challenging tasks for students and increased student commitment to learning material for its intrinsic value. Students who used a performance-approach spent more time and energy trying to enhance their performance in difficult tasks in relation to others, which worked in a typical college setting, but may provide more opportunities to lose motivation toward long-goals if the hierarchical comparisons cannot be drawn to favor these students. Students in these goal orientation states reported a perceived higher level of effort than their counterparts, especially with respect to selfimprovement, competence and learning. Students who reported experiences in college that indicated a performance-avoid approach to learning were less successful in their engineering paths and less sure of their success in an engineering program.

These findings suggest that first-generation Latina students' motivation can have a significant impact on their engineering persistence and surety of their major throughout college. In mentoring this population of students, educators and program administrators for Latinas and/or first-generation students can work to help students see and value the intrinsic thrill of mastering knowledge in engineering to meet their goals rather than making comparisons to other students. In either performance-approach or performance-avoid mastery orientations, this underrepresented group relies on affirmation from other students on external measures like grades or has to find others who are performing poorer on these external measures to feel positive about their engineering experiences. Both of these approaches to learning have possible 
pitfalls of loss of confidence and intentions to persist if failure or less than adequate performance in class occurs or the reliance on other for affirmation, respectively.

To address these issues, educators should uses appropriate learning strategies, make choices that are changing and engaging, and develop a positive orientation toward learning in their classrooms to promote a mastery orientation. As instructors, specific pedagogies can be used to influence whether students adopt a mastery orientation in the classroom. Some of these practices include focusing attention on students' effort and strategy use, not on abilities or intelligence; teaching adaptive learning strategies (e.g. planning, monitoring, and evaluating their progress in learning); encouraging student involvement and a sense of personal responsibility; deemphasizing the negative consequence of making errors; decreasing the emphasis on social comparison; and fostering the establishment of realistic, but challenging goals. By adopting these practices in the classrooms, our research suggests first-generation Latinas can be better supported in engineering. These are a few strategies that can help make the classroom environment a safe place for these underrepresented students to practice a mastery orientation without fear of failure.

Emphasis on learning rather than performing, atypical of many technical engineering courses, can improve climate in courses and help underrepresented students feel a stronger sense of belonging and inclusion in engineering which can increase persistence ${ }^{13}$. We argue that this support can produce more first-generation Latina engineering graduates which will, in turn, transform the engineering workforce to better reflect the national population. If engineering becomes more diverse, more women, especially Latinas, can see others in engineering and envision themselves in an engineering career.

\section{Strengths and Limitations}

Before concluding, it is important to address some of the strengths and limitations of this study. We evaluated this study using the four qualitative standards addressed by Frankel ${ }^{14}$ : authenticity, creditability, verification, and completeness. To allow for authenticity in the data, themes emerged through the narratives of each participant following the initial framework. Although this is a small-scale pilot study, more participant observations could be made in the future in order to get a greater distribution of themes and narratives that could add more creditability to the study. Verification was ensured by transcribing the interviews and analyzing the data by the research team. Future work includes conducting intercoder reliability testing for all inductive and deductive codes. The results of this study are only transferrable similar cases to participants. Transferability to first-generation Latinas outside of a support program like the MESA program is limited due to the increased support provided by the program. Another limitation may include the fact that AGT has primarily been a focus of motivational frameworks in quantitative analysis as opposed to a qualitative, but this might also be a strength of understanding first-generation Latinas in an engineering context. In the future, a combination of qualitative and quantitative approaches could be employed to add greater depth to the findings of the study and allow for triangulation of the findings. 


\section{Conclusion}

This article has brought attention to the personal narratives of first-generation Latina engineering students and their consequent unique experiences, challenges, motivation and persistence using the lens of AGT. Past research studies have found that persistence in one's major is highly related to the existence of formal support programs and peer support programs ${ }^{7}$. These researchers posit that if these two formal supports were strengthened, it would increase the persistence for all students. However, in this study, other supportive factors were also identified. Among the additional support factors that have contributed to the success of these firstgeneration Latinas in engineering were positive role models at home and in school, as well as encouragement from school officials. This encouragement might be salient because students from this population may not always receive support to study these subjects from these role models, so the support becomes even more notable and motivating.

However, for some participants, these same supportive factors were barriers to their success in engineering. The school system, teachers, advisors, parents, and peers can all pose challenges for these students and impede success. These findings support the idea that students require positive assistance in clarifying their educational focus as well as guidance on how to navigate the system once they are in college. In addition, the content of these narratives upheld the common perception that cultures tend "to stick together" and not intermingle. However, this tendency can hinder the future growth and success of students who find themselves in the situation of being the only one represented of their ethnicity.

Because similar factors, from the perspective of first-generation Latinas in engineering, could be supportive or restraining, AGT was used to further understand motivation for this sample of students. Although further research is needed to learn more about what specific strategies promote persistence in engineering for underrepresented students, using this theoretical framework, this research found that mastery goal orientation is a vital component of firstgeneration Latinas for success and persistence. Students emphasized self-improvement, competence and learning, and reported a greater perceived level of effort than their counterparts. In addition, a mastery goal orientation yielded greater effort during challenging tasks and increased use of student engagement and motivation in learning. Furthermore, it appears that those students who used a performance-approach used more time and energy on trying to enhance their performance on difficult tasks in relation to others.

The findings of this study suggest many important applications. Since Latino/as are the fastest growing demographic group in the United States and science, technology, engineering, and math (STEM) remain largely White and male, it is important to understand why underrepresented students choose engineering and persist in order to develop effective strategies for diversifying the engineering profession and, ultimately promoting the development of representative and innovative engineering solutions. Engineering possesses the capacity to tackle many difficult societal challenges. For this reason, a greater number of the engineering field must nurture scientists from a variety of perspectives, including those of underrepresented women. A deficit of new and diverse engineers can produce a stasis of innovation and development of new alternative and sustainable technologies. Diversity among engineers can produce a broader and exciting new range of novel products that will ultimately benefit a global society. 
Bibliography

1. Ames, C., \& Archer, J. (1988). Achievement goal in the classroom: Students' learning strategies and motivation processes. Journal of Educational Psychology, 80, 260-267.

2. Camacho, M., \& Lord, S. (2013). The Borderlands of Education: Latinas in Engineering. United Kingdom: Lexington Books.

3. Chen, X. (2005). First Generation Students in Postsecondary Education: A Look at Their College Transcripts (NCES 2005-171). U.S. Department of Education, National Center for Education Statistics. Washington, DC: U.S. Government Printing Office.

4. Cho, S., Crenshaw, K. W., \& McCall, L. (2013). Toward a field of intersectionality studies: Theory, applications, and praxis. Signs, 38(4), 785-810.

5. Creswell, J. W. (2009). Research design: Qualitative, quantitative, and mixed methods approaches. Los Angeles, CA: Sage.

6. Dweck, C. S., \& Leggett, E. L. (1988). A social-cognitive approach to motivation and personality. Psychological Review, 95, 256-27

7. Duncan, J. R., \& Zeng, Y. (2005). Women: Support factors and persistence in engineering. National Center for Engineering and Technology Education.

8. Elliot, A. J., \& Church, M. (1997). A hierarchical model of approach and avoidance achievement motivation. Journal of Personality and Social Psychology, 72, 218-232.

9. Elliot, A. J. (1999). Approach and avoidance motivation and achievement goals. Educational Psychologist, 34, 169-189.

10. Elliot, A. J., \& McGregor, H. A. (2001). A 2 x 2 achievement goal framework. Journal of Personality and Social Psychology, 80, 501-519.

11. Elliott, E. S., \& Dweck, C. S. (1988). Goals: An approach to motivation and achievement. Journal of Personality and Social Psychology, 54, 5-12.

12. Fernandez, M. J., Julie P. Martin., Zerda, K.S. \& Cortes, C. (2008). First generation college students in engineering: A qualitative investigation of barriers to academic plans. Proceedings of the 2008 Frontiers in Education Conference, Saratoga Springs, New York.

13. Foor, C. E., Walden, S. E., \& Trytten, D. A. (2007). "I Wish that I Belonged More in this Whole Engineering Group:" Achieving Individual Diversity. Journal of Engineering Education, 96(2), 103-115.

14. Frankel, R. (1999). 'Standards of Qualitative Research', in Benjamin Crabtree and William Miller (eds) Doing Qualitative Research. Thousand Oaks, CA: SAGE.

15. Gohn L. A. \& Ginger A. R., (2006). Understanding College Student Subpopulations: A Guide for Student Affairs Professionals. Retrieved September 24, 2012 from http://www.naspa.org/membership/mem/pubs/ebooks/UCCS.pdf

16. Graham, L. P. (1997). Profiles of Persistence: A Qualitative Study of Undergraduate Women in Engineering. Virginia Polytechnic Institute and State University, Blacksburg.

17. Harackiewicz, J. M., Barron, K. E., \& Elliot, A. J. (1998). Rethinking achievement goals: When are they adaptive for college students and why? Educational Psychologist, 33, 1-21.

18. Kushner, D. (2003). The Social Life of Engineers. IEEE Spectrum, 40(10), 52.

19. Kuzel, A. (1999). Sampling in qualitative inquiry. In B. Crabtree \& W. Miller (Eds.), Doing qualitative research (pp. 33-45). Thousand Oaks: Sage Publications.

20. Landis, R.B. (1991). Retention by design: Achieving excellence in minority engineering education. New York: National Action Council for Minorities in Engineering (NACME), Inc.

21. Lord, S. M., Camacho, M. M., Layton, R. A., Long, R. A., Ohland, M. W., \& Wasburn M. H. (2009). Who's persisting in engineering? A comparative analysis of female and male Asian, Black, Hispanic, Native American and White students, Journal of Women and Minorities in Science and Engineering, 15, pp. 167-190.

22. Marshall, C., \& Rossman, G. (1989). Designing Qualitative Research. CA: SAGE Publications.

23. Martin. J. P. \& Simmons, D. (2009). Work in progress - A research-based tool kit for communicating unique messages about engineering to first generation college students. Proceedings of the 2009 Frontiers in Education Conference, San Antonio, Texas.

24. McCracken, G. (1988). The Long Interview. London: SAGE Publications.

25. Meece, J. L., Anderman, E. M., \& Anderman L. H. (2006). Classroom Goal Structure, Student Motivation, and Academic Achievement, Annual. Review of Psychololgy, 57, 487-503

26. National Academy of Sciences (US), National Academy of Engineering (US), and Institute of Medicine (US) 
Committee on Maximizing the Potential of Women in Academic Science and Engineering. (2007). Beyond Bias and Barriers: Fulfilling the Potential of Women in Academic Science and Engineering. Washington (DC): National Academies Press (US).

27. Nicholls, J. G. (1984). Conceptions of ability and achievement motivation. In R. Ames \& C. Ames (Eds.), Research on motivation in education (Vol. 1, pp. 39-73). San Diego, CA: Academic Press.

28. Ohland, M. W., Brawner, C. E., Camacho, M. M., Layton, R. A., Long, R. A., Lord, S. M., \& Wasburn, M. H. (2011). Race, gender, and measures of success in engineering education. Journal of Engineering Education, $100(2), 225-252$.

29. Pascarella, E. T., \& Terenzini, P. T. (2005). How college affects students: A third decade of research (Vol. 2). San Francisco, CA: Jossey-Bass.

30. Pascarella, E.T., Pierson, C.T., Wolniak, G.C., Terenzini, P.T. (2004). First-generation college students: Additional evidence on college experiences and outcomes. The Journal of Higher Education, 75(May-June), 249-284.

31. Pintrich, Paul R. (2000). An Achievement Goal Theory Perspective on Issues in Motivation Terminology, Theory, and Research. Contemporary Education Psychology. Jan 25(1):92-104. Pintrich PR.The University of Michigan, Ann Arbor.

32. Phipps, A. (2002). Engineering women: The "gendering" of professional identities. International Journal of Engineering Education, 18, 409-414.

33. Polkinghorne, D.E. (1992) Postmodern epistemology of practice, in: S. Kvale (Ed.) Psychology and Postmodernism (pp. 146-165) London: Sage.

34. Redmond, P. (2006). Outcasts on the Inside: Graduates, employability and widening participation. Tertiary Education and Management, 12, 119-135.

35. Stephens, N. M., Fryberg, S. A., Markus, H. R., Johnson, C. S., Covarrubias, R. (2012). Unseen disadvantage: How American universities' focus on independence undermines the academic performance of first-generation college students. Journal of Personality and Social Psychology, Vol 102(6), Jun 2012, 1178-1197.

36. Tonso, K. L. (2007). On the outskirts of engineering: Learning identity, gender, and power via engineering practice. Rotterdam, Netherlands: Sense.

37. Trenor, J. M., Yu, S. L., Waight, C. L., Zerda, K. S., \& Sha, T. L. (2008). The relations of ethnicity to female engineering students' educational experiences and college and career plans in an ethnically diverse learning environment. Journal of Engineering Education, 97(4), 449-465.

38. U.S. Department of Education. (2010) National Center for Education Statistics [NCES]. Web tables: Profile of undergraduate Students 2007-2008. Retrieved July 10, 2012 from http://nces.ed.gov/pubs2010/2010205.pdf

39. U.S. Department of Education. (2006). A test of leadership: Charting the future of U.S. higher education. Washington, DC: Author.

40. Warburton, C. E., Bugarin, R., \& Nunez, M. A. U.S. Department of Education, National Center for Education Statistics. (2001). Bridging the Gap: Academic Preparation and Postsecondary Success of First-Generation Students, NCES 2001-153, by Washington, DC. Retrieved July 25, 2012 from http://nces.ed.gov/pubs2001/2001153.pdf

41. Wentzel K. R., Wigfield A. (2009). Handbook of Motivation at School, New York: Taylor \& Francis Group.

42. Wolf, W. A. (2006). Diversity in engineering. Women in Engineering ProActive Network.

43. Yoder, B.L. (2013). Engineering by the Numbers (p. 37). Retrieved from http://www.asee.org/papers-andpublications/publications/14_11-47.pdf

44. York-Anderson, D. C., \& Bowman, S. L. (1991). Assessing college knowledge of first-generation and secondgeneration college students. Journal of College Student Development, 32, 116-122.

45. Yu, S.L., Martin, J. P., Waight, C.L., \& Zerda. K.S. (2009). Ethnic identity, belonging, and achievement goals among women in engineering. Paper presented at the 2009 American Psychological Association Convention, Toronto, Canada.

46. National Center for Education Statistics. (2010). Status and trends in the education of racial and ethnic groups (NCES 2010-015).

47. Mattern, R., A. (2005). College Students' Goal Orientations and Achievement. International Journal of Teaching and Learning in Higher Education, 17(1), 27-32.

48. Harackiewicz, J. M., Barron, K. E., Pintrich, P. R., Elliot, A. J., \& Thrash, T. M. (2002). Revision of achievement goal theory: Necessary and illuminating. Journal of Educational Psychology, 94(3), 638-645.

49. Meece, J. L., Anderman, E. M., \& Anderman, L. H. (2006). Classroom goal structure, student motivation, and academic achievement. Annu. Rev. Psychol., 57, 487-503. 